ISBN 978-81-943403-5-5

18th ROME - ITALY International Conference on Art History, Literature, Social Sciences and

Education (AHLSE-20)

Rome (Italy) Feb. 3-5, 2020

\title{
Information Literacy Levels of Wanni Community in Nuwara Kalawiya, North Central Province (Anuradhapura District) in Sri Lanka: A Survey
}

\author{
K.R.N Harshani ${ }^{1}$, A.S Siriwardana ${ }^{2}$ and J.M.S Dilinika ${ }^{3}$ \\ ${ }^{1}$ Senior Assistant Librarian, University of Rajarata, Sri Lanka \\ ${ }^{2}$ Librarian, University of Rajarata, Sri Lanka. Email: ssasoka@gmail.com \\ ${ }^{3}$ Lecturer, Department of Library and Information Science, University of Kelaniya, Sri Lanka
}

\begin{abstract}
A community identified as the 'Wanni' people are found in the arid forest areas of Nuwara Kalaviya centered on Anuradhapura District in Sri Lanka. It encompasses thirty-five villages from which 173 families have been selected for collective interviews. The study focuses to identify the literacy levels of Wanni People and suggestion were made to improve information literacy their skills.
\end{abstract}

Keywords: Wanni Community, Information Literacy, Nuwara Kalaviya, Veddas People, Sri Lanka

\section{Introduction}

Sri Lanka as a country is developing rapidly in various sections. Also, Sri Lanka is known for its cultural diversity community variations. As a result of that Sri Lanka contains indigenous community called "Wanni Community" who is a category of Veddas People. A community identified as the "Wanni' people are found in the arid forest areas of Nuwara Kalaviya centred on Anuradhapura. The livelihood of these people had been hunting, collecting bee honey, and other forest products such as tubers, roots, and fruits in the wild. They are distinctly different from the Veddas communities, and as a group, lead independent lives. These people have their own cultural traits and social behaviors.

The Veddas of Sri Lanka have been the pioneers of the island for centuries and millennia. Veddadescent spans for well over 30,000 years whereas some believe that the Veddas pre-date the descendance, the King Vijaya's arrival in the country 2,500 years ago. However, there are sufficient evidences to confirm that the Vedda heritage dates back 34,000 years (de Silva 1972and Dharmadasa 1990). In 17th century Robert Knox described them as "wild men". According to the Encyclopedia, the Veddas constitute only a very small proportion of the total population of Sri Lanka, which was estimated at nearly 15 million by the 1981 census. There is, however, no consensus as to just how small this proportion is, because the criteria used to identify the Veddas vary widely. They were last enumerated separately in the census of 1963, at which time they numbered 400. In 1970, however, a census of the Anuradhapura Veddas, conducted as part of an Ethnographic study, counted more than 6,600 of them. It also describes the differences between Veddas community according to their demographic area. According to that, Wild," "Jungle," or "Rock Veddas," who live from hunting and gathering and sometimes also shifting cultivation, and "Village Veddas," who live in permanent settlements and subsist principally from cultivation, is long established, but already by the time of the Seligmanns' study there were very few Veddas who lived principally from foraging. The Anuradhapura Veddas until recently have derived their living mainly from shifting cultivation, supplemented where possible by wet-rice agriculture. 
Accordingly, though wanni people are a category of Veddas people they are differs from Veddas people according to their social behavior. The Wanni people living in several villages of Anurdhapura district while facing numerous difficulties due to social and economical changes. Poverty, Education and Literacy are the main factors which are leading to this situation. In this context, the research is to study their education levels and literacy skills. Education can play a key role in any community to uplift their literacy levels. According to that the research will be very important to study their education levels and literacy skills for the benefit of their community.
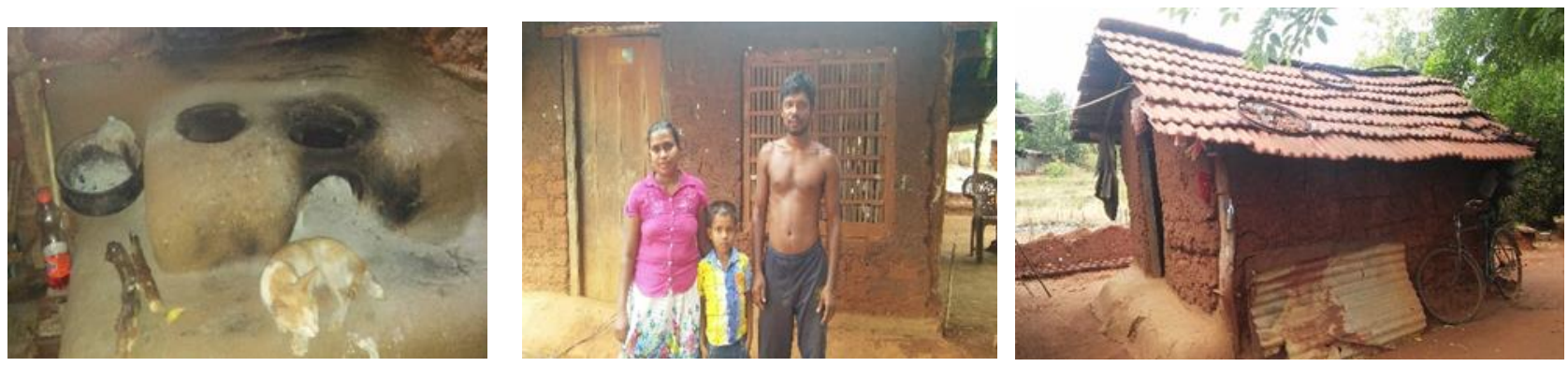

Fig. 1: Wanni Community

Source: Research Data, 2019

\section{Statement of the Problem}

How the current educational and cultural changes have affected to improve education and literacy levels of Wanni Community in Nuwara Kalawiya?

Due to social changes and economic developments, every country and its people changing rapidly in their thoughts and behaviors. For the past 25 years these displaced group of Wanni Community have struggled to live in these colonies. Their cultural heritage was influenced by the neighboring cultures. Today only a few remaining Wanni Community still manage to preserve their cultural identity despite relentless pressure from the surrounding dominant communities.( IJSRP, 2017)According to that social changes, education also has become a major factor of this revolution. This paper focuses education and literacy levels of wanni community of Anuradhapura, Sri Lanka.

\section{Objectives of the research}

1. To identify Wanni Communities in Nuwara Kalawiya

2. To identify Social Background of Wanni Community in Nuwara Kalawiya

3. To identify Literacy levels of Wanni Community

\section{Methodology}

\subsection{Sample of the study}

There are 09 provinces in Sri Lanka, among those districts, Anuradhapura and Vaunia (02) Districts were selected as the sample of the study. The Sample consisted 173 families among Wanni Community.

People in following divisional secretariat areas of Nuwara kalawiya and Vaunia as follows : Vauniya, Kuda Kumbukgollawa ,Medwachchiya, Rambewa, Kahatagasdigiliya, Madyama Nuwaragam Palatha, Mahawilachchiya Kabithigollawa. This research covered 35 Grama Niladhari (Government Servants) areas of above divisional secretariat areas of Nuwara Kalaviya. 173 of Families were interviewed and observed in this research. 


\subsection{Data Collection Method}

Data were collected from Wanni Community, Nuwara Kalawiya in Anuradhapura district and Vaunia and data were collected through face-to- face interviews, field visits and questionnaires. Field visits were very important to observe the current situation of the community and it helped to collected several facts related to their literacy levels

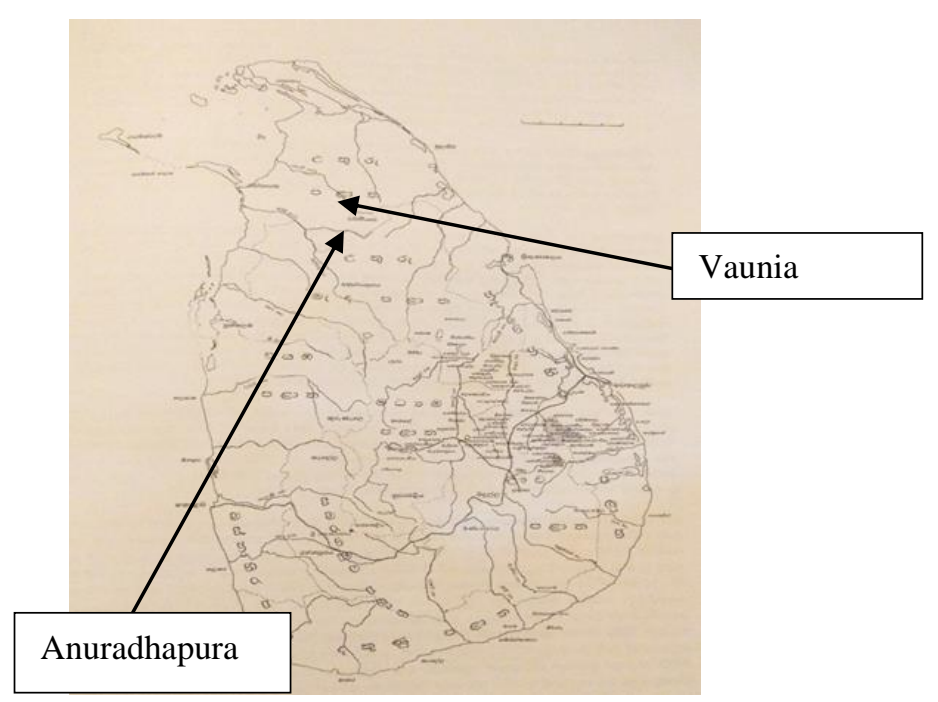

Fig. 2: Map of Sri Lanka

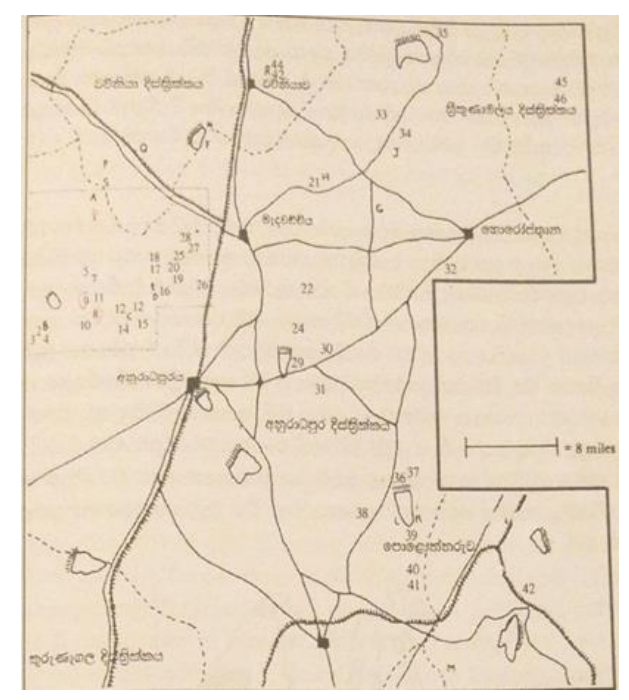

Fig. 3: Sample areas of Wanni Villages

\section{Results and Discussion}

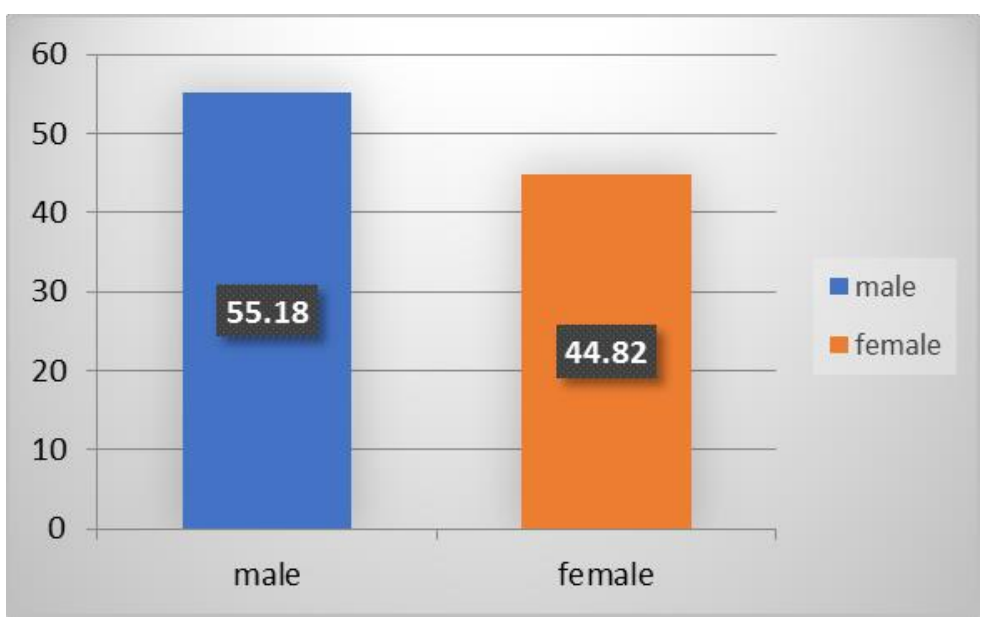

Fig. 4: sample of the study

According to total respondents, $55 \%$ were males while $45 \%$ were females and the sample represented 35 Grama Niladhari areas of Nuwarakalaviya. 


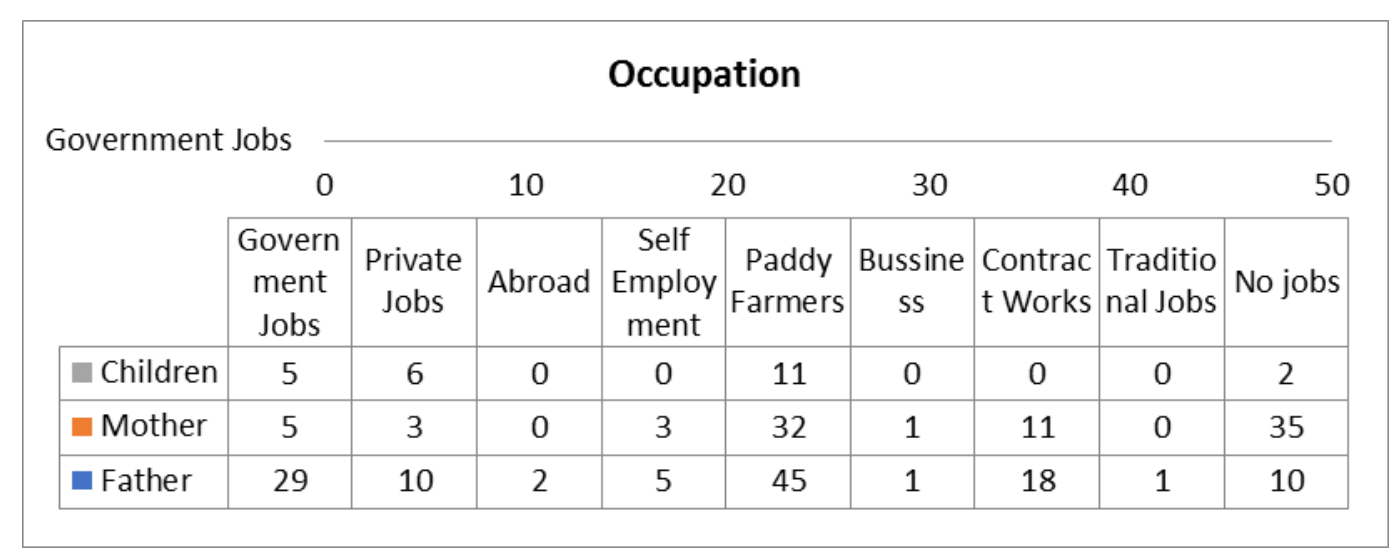

Fig. 5: Occupation details of Wanni People

According to table 2, the majority of respondents were paddy farmers. It was the main occupation of Veddas people in Nuwarakalaviya. A considerable amount of male respondents were engaged in government jobs and contract works as their occupation. It could identify that the majority of female respondents has no jobs and they engaged in household works.

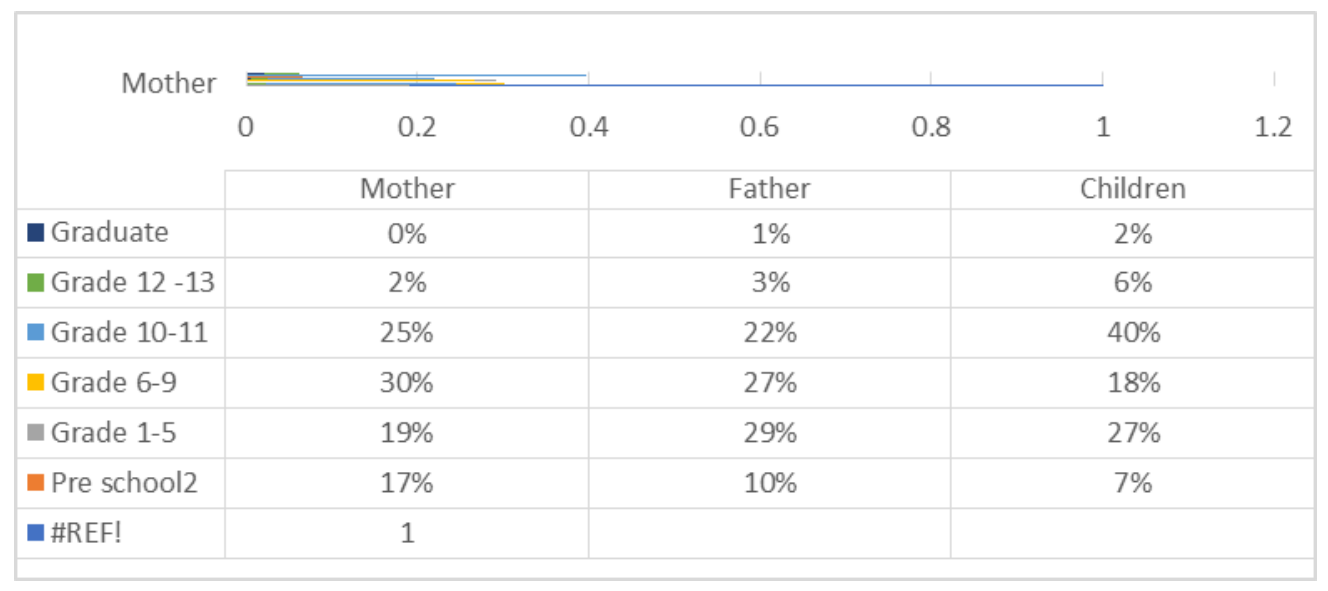

Fig. 6: Educational levels of Wanni People

According to Chart 03 majority of parents did not have Secondary level education and most were in grade 69 education level. Accordingly, 2\% percent of Mothers and 3\% percent of Fathers had Secondary education. When considering the status of their children, it would be able to identify that most of children moved forward to Secondary education. Accordingly, $40 \%$ percent highlighted that they had secondary education. Among the children, only $2 \%$ percent were graduates. In conclusion, most of parents need to qualify their students in education field to overcome problems that they have faced at their ages. 


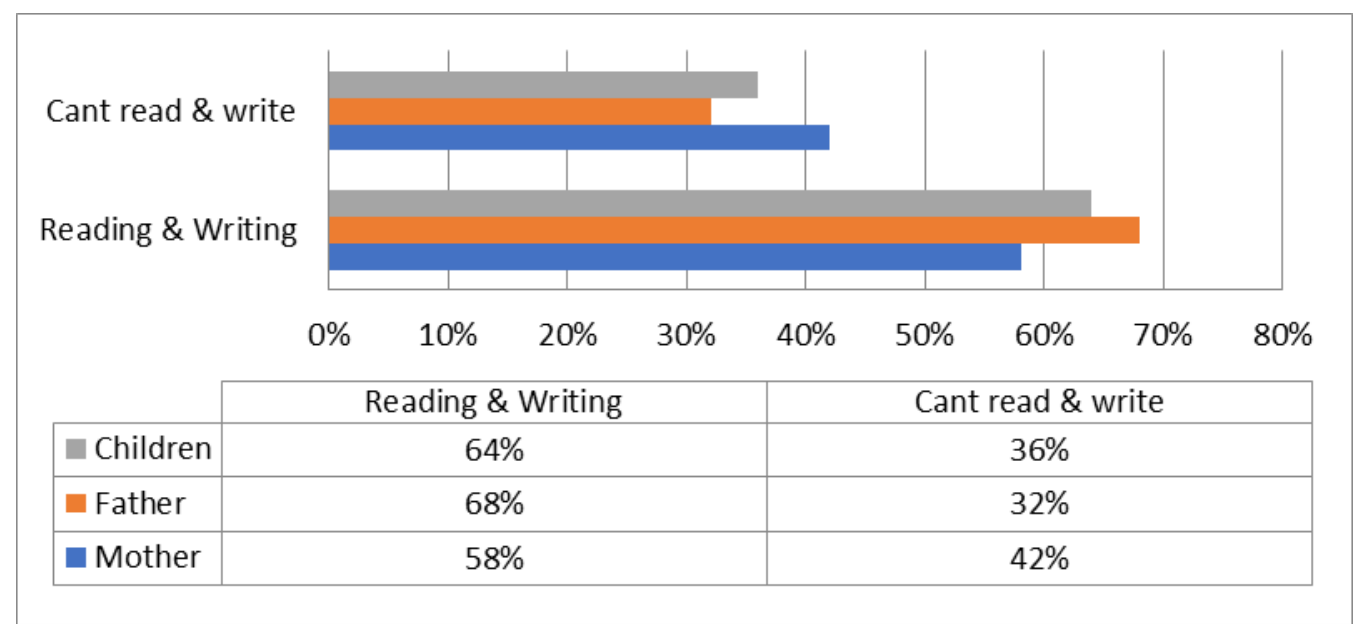

Fig. 7: Literacy Skills

According to the population of this research, Reading and writing are the basic skills of information literacy. (IL) $68 \%$ of fathers have reading and writing ability and $32 \%$ of people were not familiar with reading and writing skills. While $58 \%$ of mothers have reading and writing abilities, still $42 \%$ did not have those skills. According to the results $64 \%$, children had reading and writing skills while $36 \%$ did not have those skills. Parents of above mentioned community who are always motivating their children to do higher studies such as $\mathrm{A} / \mathrm{L}$ and university education.

According to figure 8, Radio was the most popular communication way among the respondents. $84 \%$ of respondents use radios to get information. $50 \%$ of respondents use Television (TV) to find information while $37 \%$ use libraries to seek information for their needs. Percentages for Gossips, Newspapers and Internet were 24\%, 21\% and 13\% respectively. Because of latest technology and social changes, the internet could get a considerable value of this sample. Moreover, most of respondents of the sample use mobile phones to search information using internet.

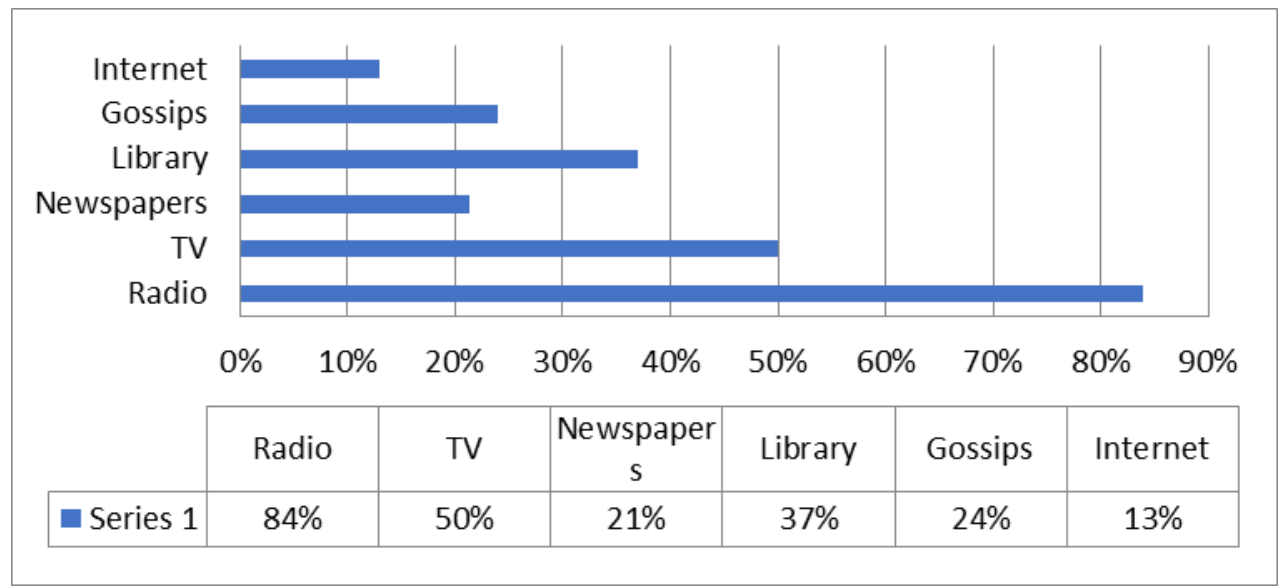

Fig. 8: Information searching strategies

\section{Conclusion and suggestions}

This research examined Information literacy levels of Wanni Community in Nuwara Kalawiya Sri Lanka. It was identified that current educational and cultural changes have affected to improve literacy levels of Wanni Community in Sri Lanka. As any community, Wanni Community also changing with social trends and its 
benefits. They are exposing to the society with information literacy. As a result of that they have good percentages for education section. Most of the young people have reading, writing ability and they have a good influence to do higher studies. Because of new technology, internet and electronic media also rising up with Wanni Community information searching strategies. Better Information flow is the most effective way to develop any community with knowledge. In this context, proper infrastructure facility on education, resources and equal learning opportunities should be provided to uplift wanni community's literacy levels parallel with

other communities in Anuradhapura District. In addition, systematic information awareness programs and literacy programmes need to be implemented mainly by the libraries for further developments

\section{References}

[1] Deraniyagala S, U (1992) Pre history of Sri Lanka, An Ecological Perspective. Department of Archaeological Survey, Government of Sri Lanka.

[2] Dharmadasa, K. N.O and S. Samarasinghe (eds.) (1990). The Vanishing Aborigines. International Center for Ethnic Studies (ICES). Sri Lanka

[3] Gananath Obeysekara (1990) Colonial Histories and Vedda Primitivism: An Unorthodox Reading of Kandy Period Texts Kandy, Sri Lanka

[4] Gunawardhana, P \& Adhikari, G (2010) Wadi Jana Urumaya, Neptune, Colombo.

[5] International Journal of Scientific and Research Publications, Volume 7, Issue 4, April 2017 